\title{
Association between asthma and clinical mortality/morbidity in COVID-19 patients using clinical epidemiologic data from Korean Disease Control \& Prevention
}

\author{
Hyo Geun $\mathrm{Choi}^{1}$, Jee Hye Wee ${ }^{1}$, So Young Kim ${ }^{2}$, Joo-Hee Kim ${ }^{1}$, Hwan Il Kim ${ }^{1}$, Ji-Young \\ Park $^{1}$, Sunghoon Park ${ }^{1}$, Young Il Hwang ${ }^{1}$, Seung Hun Jang ${ }^{1}$, and Ki-Suck Jung ${ }^{1}$ \\ ${ }^{1}$ Hallym University Sacred Heart Hospital, Hallym University College of Medicine \\ ${ }^{2}$ Bundang CHA Medical Center
}

October 10, 2020

\begin{abstract}
Background: The role of asthma as a risk factor for coronavirus 2019 (COVID-2019) morbidity and mortality is inconclusive and not fully understood. The primary objective was to evaluate the association between asthma history and mortality of COVID-19, and the secondary objective was to analyze the risk of COVID-19-related outcomes among patients with asthma compared to those without. Methods: Using clinical epidemiologic data from Korean Disease Control \& Prevention, the risk for COVID-19-related morbidity and mortality were compared in patients with asthma and those without asthma among the participants who were confirmed to have COVID-19. A Cox proportional hazards regression model was used for mortality, and a linear regression model was used for morbidity scores. Results: The hazard ratio for death of patients with asthma versus those without was 2.48 (95\% confidence interval $(\mathrm{CI}) 1.21-5.08, \mathrm{P}=0.013)$ and $2.20(95 \% \mathrm{CI} 1.02-4.76, \mathrm{P}=0.045)$ after full adjustment. The comorbidity of asthma was associated with an increase in the maximal morbidity score of COVID-19 compared to no asthma (estimated value of morbidity score $(\mathrm{EV})=0.44,95 \% \mathrm{CI} 0.16-0.73, \mathrm{P}=0.003)$. Conclusion: Asthma is associated with an increased risk of mortality and morbidity in the Korean nationwide COVID-19 registry.
\end{abstract}

\section{Hosted file}

Complete manuscript with tables_1009_2020.pdf available at https://authorea.com/users/366143/ articles/485955-association-between-asthma-and-clinical-mortality-morbidity-in-covid-19patients-using-clinical-epidemiologic-data-from-korean-disease-control-prevention

\section{Hosted file}

Figures.pptx available at https://authorea.com/users/366143/articles/485955-associationbetween-asthma-and-clinical-mortality-morbidity-in-covid-19-patients-using-clinicalepidemiologic-data-from-korean-disease-control-prevention 